Motrivivência v. 29, n. 50, p. 31-49, maio/2017

http://dx.doi.org/10.5007/2175-8042.2017v29n50p31

\title{
DESENVOLVIMENTO HUMANO E TRANSMISSÃO DE VALORES NOS PROJETOS SOCIOESPORTIVOS DO INSTITUTO COMPARTILHAR: a perspectiva dos ex-alunos
}

\author{
Ana Elisa Guginski Caron? \\ Tatiana Sviesk Moreira ${ }^{2}$ \\ Gilmar Francisco Afonso 3 \\ Wanderley Marchi Júniort
}

\begin{abstract}
RESUMO
O objetivo desta pesquisa é analisar o impacto da proposta metodológica do Instituto Compartilhar (IC) por meio da percepção dos ex-alunos que participaram dos seus projetos socioesportivos. Para tanto, avaliamos 738 questionários respondidos via online pelos ex-alunos do IC. Com base nas respostas, identificamos que a participação em um projeto pode ser sim uma possibilidade de interiorização de valores sociais e de contribuição para o desenvolvimento humano, pois 90,40\% dos respondentes afirmaram que, durante o tempo de participação no projeto, aprenderam a trabalhar em equipe, $88,80 \%$ deles aprenderam a respeitar e $78 \%$ afirmaram que o projeto contribuiu para o seu desenvolvimento como cidadão. Ao considerarmos que $63 \%$ dos ex-alunos afirmaram que aprenderam a jogar muito bem o voleibol, concluímos também que a metodologia utilizada pelo IC cumpre com um dos seus objetivos que é ensinar uma modalidade esportiva.
\end{abstract}

Palavras-chave: Projetos Socioesportivos; Iniciação Esportiva; Valores Sociais; Desenvolvimento Humano

1 Mestranda em Educação Física. Universidade Federal do Paraná (UFPR). Curitiba/Paraná, Brasil. E-mail: anaecaron@gmail.com

2 Doutoranda em Educação Física. Universidade Federal do Paraná (UFPR). Curitiba/Paraná, Brasil. E-mail: tatisviesk@hotmail.com

3 Doutor em Sociologia. Professor da Universidade Tecnológica Federal do Paraná (UTFPR). Curitiba/Paraná, Brasil. E-mail: gildoxyz@hotmail.com

4 Pós-Doutor em Sociologia. Professor da Universidade Federal do Paraná (UFPR). Curitiba/Paraná, Brasil. E-mail: wmarchijr@gmail.com 


\section{INTRODUÇÃO}

O Instituto Compartilhar (IC) é uma organização sem fins lucrativos que gerencia projetos sociais de iniciação esportiva e de desenvolvimento de valores por meio da prática do voleibol. O fundador do IC é o atual técnico da seleção brasileira masculina de voleibol, Bernardo Rocha de Rezende, conhecido como Bernardinho. A idealização da organização não governamental (ONG) advém da experiência do projeto Centro Rexona de Excelência do Voleibol, que surgiu em Curitiba no ano de 1997 junto com a equipe profissional de voleibol feminino chamada Rexona ${ }^{5}$. Este projeto englobava a equipe profissional e também uma iniciativa social que visava proporcionar melhores condições de vida para as crianças e adolescentes atendidos, através dos valores aprendidos por meio da iniciação à prática do voleibol. Em 2003 a equipe profissional se transferiu para o Rio de Janeiro, porém o braço social do projeto se manteve em Curitiba e em algumas outras cidades do Paraná (INSTITUTO COMPARTILHAR, 2007).

O IC foi idealizado com base na crença de que o ensino do voleibol pode ser uma possibilidade profícua de modificação da realidade social de crianças. A partir de 2005, o projeto já em funcionamento no estado do Paraná foi expandido para outros polos como Rio Grande do Sul, São Paulo, Rio de Janeiro, Minas Gerais e Rio Grande do Norte. No ano de 2014, o IC atendeu aproximadamente 4200 alunos com faixa etária entre nove e 15 anos, em 42 núcleos em seis estados do Brasil (INSTITUTO COMPARTILHAR, 2015).

A atuação do IC se dá por meio da elaboração e da implantação dos projetos prioritariamente nas escolas públicas em diferentes realidades sociais do Brasil, da disponibilização do material apropriado para o ensino do voleibol a partir da metodologia desenvolvida pelo projeto, do refinamento desta metodologia que lhe é própria, da capacitação de professores e profissionais que atuam diretamente nos núcleos, do acompanhamento das atividades desenvolvidas em cada núcleo e da constante elaboração de instrumentos de avaliação.

A Metodologia Compartilhar de Iniciação ao Voleibol, própria do IC, preconiza o jogo do minivôlei para o ensino das capacidades físicas, técnicas e táticas do voleibol, bem como para a transmissão dos valores sociais. Tal metodologia tem como fundamento a adaptação do tamanho de quadra, altura de rede, tamanho de bola e número de jogadores por equipe de acordo com as capacidades físicas e necessidades específicas de cada faixa etária. Os alunos são divididos nas turmas de acordo com suas idades em diferentes categorias. A saber, crianças de nove e 10 anos participam da categoria "Mini 2x2", crianças de 11 e 12 anos participam da categoria "Mini 3x3", adolescentes de 13 anos participam da categoria "Mini 4x4" e adolescentes de 14 e 15 anos participam da categoria "Vôlei" (INSTITUTO COMPARTILHAR, 2014). A nomenclatura de cada categoria está diretamente relacionada ao número de jogadores por equipe, ou seja, no "Mini 2×2" cada equipe é

5 No contexto, firmou-se uma parceria entre a Unilever a partir da marca de desodorantes Rexona, o Governo do Estado do Paraná e os municípios cujas escolas públicas passariam a acolher o projeto e o então técnico da seleção brasileira, o Bernardinho. O time de voleibol feminino Rexona foi finalista nas três edições da Superliga que disputou, sagrando-se bicampeão em 1997/98 e 1999/00 e vice-campeão em 1998/99. (VLASTUIN, 2008). 
composta por dois jogadores, no "Mini 3x3" por três jogadores, no "Mini 4x4" por quatro jogadores e no "Vôlei", o número oficial de seis jogadores.

Essa metodologia, aprimorada desde 1997, apresenta uma vertente de ensino de valores sociais através da prática esportiva. Isso se reflete no investimento que se faz no sentido de articular a iniciação esportiva ao ambiente educacional e familiar para que efetivamente possa ocorrer a internalização desses valores que são fundamentais para operar as mudanças sociais almejadas pelo projeto. Os valores são trabalhados por meio dos próprios exercícios propostos nas aulas, bem como em atividades pontuais e também em eventos, sendo eles esportivos ou não. De acordo com a Metodologia Compartilhar de Iniciação ao Voleibol, o trabalho com cada categoria enfatiza um valor específico: o valor cooperação é enfatizado na categoria "Mini 2x2", a responsabilidade na categoria "Mini $3 \times 3$ ", o respeito na categoria "Mini $4 \times 4$ " e a autonomia na categoria "Vôlei" 6 (INSTITUTO COMPARTILHAR, 2012).

O documento "Desenvolvimento de Valores na Metodologia Compartilhar de Iniciação ao Voleibol" aponta a Teoria Cognitiva de Piaget e a Teoria da Universalidade dos Princípios Morais de Kohlberg como base para a conceituação dos valores específicos enfatizados nas categorias (INSTITUTO COMPARTILHAR, 2011). Esse documento apresenta a definição de cooperação como sendo a importância de coordenar ações, através de relacionamentos harmoniosos, para atingir um objetivo comum; a responsabilidade como a atitude de ser o respeito como a compreensão e aceitação das diferenças, prezando pela integridade física e mental dos demais, colocando-se no lugar do outro; e a autonomia é conceituada como a capacidade de iniciar ações por conta própria (INSTITUTO COMPARTILHAR, 2011)

As aulas nos projetos acontecem no contra turno escolar dos participantes, duas vezes por semana e têm a duração de 50 minutos. A seleção dos alunos para participarem das aulas passou por diferentes formatos durante a existência do IC. Nos anos iniciais realizava-se um teste baseado em critérios técnicos e também físicos, como altura dos candidatos. Com o amadurecimento das ações e consequente refinamento dos objetivos do IC, passou-se a adotar uma lista de espera e assim que existem vagas ociosas os inscritos são chamados pela ordem de inscrição. No caso do início de atividades de um núcleo é realizado um sorteio entre os inscritos para definir os primeiros participantes (INSTITUTO COMPARTILHAR, 2007). Cerca de 90\% dos núcleos estão localizados dentro de escolas públicas, o que favorece a relação dos projetos com a educação formal e permite que os professores dos projetos acompanhem o desempenho dos alunos tanto no ambiente escolar como nas aulas do projeto ${ }^{7}$. Os outros $10 \%$ dos núcleos se localizam em ginásios públicos e reúnem alunos de diferentes escolas.

6 Um curso de credenciamento na Metodologia Compartilhar de Iniciação ao Voleibol é oferecido aos professores antes de os mesmos assumirem as aulas. Os professores recebem uma apostila com todas as orientações da metodologia e devem realizar o planejamento de todas as aulas. A cada dois anos é realizado um encontro entre os profissionais que atuam nos projetos com o objetivo de aprimorar a metodologia utilizada. Uma equipe de coordenadores acompanha o andamento dos projetos por meio de relatórios mensais enviados pelos professores e também por visitas técnicas locais (INSTITUTO COMPARTILHAR, 2013).

7 Os professores do projeto fazem o acompanhamento do rendimento escolar dos alunos por meio do boletim escolar. 
A inserção dos alunos no ambiente esportivo também se faz para além das aulas, por meio de eventos e campeonatos organizados pelo IC. Esses eventos buscam apresentar uma relação com os valores prioritários da metodologia, dentre outras formas, proporcionando intercâmbio entre os alunos de diferentes projetos. Temas correlatos à prática esportiva são abordados através de atividades específicas ou palestras com profissionais da área de nutrição, medicina ou psicologia, por exemplo, com vistas a ampliar os conhecimentos dos alunos (INSTITUTO COMPARTILHAR, 2013).

No ano de 2013, após 17 anos de atuação e mais de 20 mil alunos atendidos pelos projetos, o IC identificou a necessidade de desenvolver uma pesquisa para avaliar o impacto da participação nos projetos na vida dos ex-alunos. Um dos principais pontos de interesse desta pesquisa foi investigar se houve a incorporação dos valores ensinados durante as atividades esportivas. Neste sentido, foram distribuídos questionários para os ex-alunos do projeto. A pesquisa foi realizada entre agosto e dezembro de 2013 com a divulgação dos resultados finais no relatório anual do IC referente as atividades do ano de 2014, publicado em 2015 (INSTITUTO COMPARTILHAR, 2014).

A realização dessa pesquisa suscita a discussão sobre os efeitos da participação em projetos sociais e esportivos, bem como sobre os resultados efetivos desses projetos. A validade de entrevistarmos ex-alunos se sustenta por entendermos que a transferência do modo de agir pautado em valores sociais apreendidos no esporte para diferentes esferas da vida não ocorre numa relação de causa-efeito e, por este motivo, não pode ser "aferida" imediatamente após uma aula na qual se foi enfatizado determinado valor, pois a mesma demanda tempo, depende dos lugares onde o aprendiz transita/interage e está circunscrita na complexidade das relações sociais a que o aluno está constantemente exposto.

Castanheira (2008) salienta que o advento de $\mathrm{ONG}^{8}$ promovendo projetos socioesportivos a partir da década de 1990, destacou a dimensão educacional do esporte, seu uso como instrumento de transmissão de valores morais e seu papel socializador. Para Vianna e Lovisolo (2009), o grande número de projetos esportivos que têm jovens de classes populares como público alvo reforça o papel do esporte como um elemento de socialização ou inclusão social. A visão de Barbirato (2005) corrobora com a dimensão educacional do esporte e também com a função dos projetos esportivos que aliam educação e ensino de habilidades esportivas e atuam no desenvolvimento humano em várias áreas como pessoal, social além da esportiva.

Estudos apontam que a prática de atividades esportivas pode contribuir para o ensino de valores e o desenvolvimento de habilidades sociais (SANCHES e RUBIO, 2011; HOLT et al., 2011; SKINNER, ZAKUS e COWELL, 2008). Holt e Neely (2011) destacam a melhora no relacionamento com os técnicos, o trabalho em equipe, relacionamento com novas amizades, controle emocional e confiança como benefícios da prática esportiva para jovens.

8 Surgiu pela primeira vez na Organização das Nações Unidas (ONU) após a Segunda Guerra Mundial para designar organizações supranacionais e internacionais que foram estabelecidas por acordos governamentais. Para Silveira (2007, p. 80) "as ONGs podem ser consideradas como corpos intermediários entre o Estado e o mercado, com a clara intenção de 'consertar' as deficiências da ação estatal e também os malefícios causados pelo mercado". No Brasil as ONGS surgem nas décadas de 1960 e 1970, com expansão considerável a partir da década de 1980. 
Entretanto, outras pesquisas mostram que existem várias barreiras para que esses benefícios sociais sejam realmente alcançados pelos participantes. Entre essas barreiras, é possível destacar a formação e a visão filosófica do profissional que atua diretamente com as crianças e adolescentes (SANCHES e RUBIO, 2011; KOH e CAMIRÉ, 2015); o tempo de permanência dos participantes nos projetos (VIANA e LUVISOLO, 2009), a falta de avaliação dos resultados alcançados (BAILEY, 2005) e dificuldades de coerência metodológica entre os objetivos estimados e as atividades propostas (HIRAMA, 2008).

A atuação de ONGs que utilizam o esporte como meio de transformação social e educação ressalta a crença do esporte como elemento capaz de melhorar a qualidade de vida do público-alvo de seus projetos esportivos (SILVA, 2010). Para Stigger e Thomassin (2013) os projetos esportivos assumem uma pretensão educativa que, por meio das particularidades do esporte como, o respeito às regras e o trabalho em equipe nos esportes coletivos, podem potencializar o ensino de conteúdos simbólicos que serão úteis para a solução de outros problemas da vida das crianças e adolescentes.

Entretanto, apesar dos estudos apresentados apontarem para os efeitos positivos da prática esportiva e dos programas sociais que utilizam o esporte como ferramenta de educação para crianças e jovens é necessário aprofundar a análise e compreender todas as dimensões desse fenômeno social. Bracht (1992) discute a utilização do modelo hegemônico do esporte como ferramenta de educação, principalmente nas aulas de educação física. Nesse sentido, a utilização de um único modelo de esporte pautado no rendimento pode estimular a competição exacerbada, busca da vitória a qualquer preço, a exclusão dos menos habilidosos e a obediência a regras sem questionamentos. O autor supracitado aponta para o papel funcionalista do esporte dentro da sociedade capitalista que promove a reprodução sem reflexão.

Conforme Coakley (2014), o esporte é compreendido pela sociedade como um grande mito, como se ele fosse inerentemente bom e puro. Dessa forma, a prática esportiva garantiria ao praticante o aprendizado de somente atributos positivos, não limitando esses benefícios às pessoas, mas expandindo suas utilidades para o desenvolvimento de comunidades. A crítica de Coakley (2014) aponta para a necessidade de relativizar a ação de causa-efeito atribuída aos praticantes esportivos e principalmente a crianças e jovens participantes de projetos sociais ou de atividades com objetivos de educação através do esporte. Ou seja, a dimensão "salvacionista" atribuída ao esporte precisa ser discutida à luz de entendimentos sobre os significados atribuídos dentro do contexto sociocultural de quem o pratica e da pedagogia utilizada no seu ensinamento, a fim de garantir os benefícios a que se propõe, sejam eles no desenvolvimento pessoal - com ensino de valores e outras condutas morais - ou comunitário.

Torna-se também relevante a reflexão e o conhecimento acerca dos atributos do esporte espetacularizado e mercantilizado ${ }^{9}$, ao considerarmos as relações de interesse

9 Marchi Jr. (2004) analisa as modificações históricas que perpassaram as fases de amadorismo, profissionalização e espetacularização do voleibol apontando para um modelo que, pautado no interesse midiático, empresarial e político, paulatinamente passou a enfatizar o consumo do voleibol. A lógica comercial na qual o esporte se 
estabelecidas no interior do campo esportivo e a reprodução de lógicas não necessariamente ajustadas ao caráter educacional deste fenômeno social. Portanto, entendemos que, caso as ações de projetos esportivos não estejam filosoficamente fundadas na perspectiva educacional e social, as suas propostas podem ser distorcidas e até mesmo gerar efeito contrário, como a incorporação dos valores que a competitividade exacerbada tende a veicular.

Foi no intuito de verificar a efetividade da proposta e da metodologia do IC que realizamos esta pesquisa, objetivando analisar o impacto da participação de crianças e jovens nos seus projetos socioesportivos com base na percepção dos ex-alunos. Apesar da utilização de parte das informações obtidas na pesquisa feita pelo IC, o artigo apresenta uma análise imparcial dos dados apresentados.

\section{METODOLOGIA}

Esta pesquisa se caracteriza como descritiva, seguindo o conceito de Gil (1999) que aponta a principal finalidade desse tipo de pesquisa a descrição das características de determinada população, fenômeno ou grupo. A pesquisa descritiva também levanta as opiniões e atitudes a cerca de um fenômeno, estabelecendo relações entre as variáveis.

Como parte da estratégia para avaliar a percepção que os ex-alunos têm sobre o sentido que a participação no projeto tomou em suas vidas, utilizou-se da técnica de questionário. Segundo Gil (1999, p. 128), o questionário pode ser definido:

[...] como a técnica de investigação composta por um número mais ou menos elevado de questões apresentadas por escrito às pessoas, tendo por objetivo o conhecimento de opiniões, crenças, sentimentos, interesses, expectativas, situações vivenciadas etc.

Considerando essas características, as perguntas do questionário foram elaboradas com a intenção de investigar como os alunos significam a sua passagem pelo projeto, se aprenderam a jogar voleibol, como e se eles assimilaram os valores ensinados e se pode ter ocorrido a transferência desses valores para as outras esferas das suas vidas. O questionário contém 32 perguntas fechadas de múltipla escolha e atribuição de notas de 5 a 10 (sendo 5 a pior avaliação e 10 a melhor avaliação) e 4 perguntas abertas, além dos dados de identificação como nome, data de nascimento e e-mail.

Esse questionário online foi disponibilizado no Facebook do Instituto Compartilhar e enviado por e-mail para a listagem de contato cadastrados no site do IC. Como estratégia para a divulgação do questionário foi criada a campanha "Ex-aluno, por onde você anda?" e diferentes anúncios foram colocados no site e no Facebook do IC no período agosto a dezembro de 2013 solicitando que os ex-alunos respondessem o questionário (INSTITUTO COMPARTILHAR, 2014).

encontra inserido, caso não seja identificada e compreendida, tende a limitar o seu potencial alcance social nas suas outras manifestações que não a de alto rendimento, em função da valorização do resultado esportivo em oposição ao desenvolvimento de valores e aprendizado das habilidades esportivas que compõem a sua prática. 
Participaram da pesquisa 738 ex-alunos de diferentes núcleos do IC. Os egressos que responderam ao questionário são nascidos entre os anos de 1981 e 2002. A distribuição etária foi de $12,23 \%$ na faixa etária de 12 a 15 anos, 41,71\% de 16 a 20 anos, $32,47 \%$ de 21 a 25 anos e 13,59\% de 26 a 33 anos. Observada a variação de 21 anos de idade, caracterizamos o perfil etário dos participantes como heterogêneo, fato que confere à pesquisa uma multiplicidade de olhares sobre a possível incorporação de valores com base nas respectivas vivências no projeto. Esta variação também sugere que, ao passo que alguns participantes estão mais distantes temporalmente das ações no projeto, outros ainda podem estar envolvidos com a filosofia do mesmo. Ainda traçando um perfil dos respondentes, no tocante ao grau de escolaridade, 11\% dos egressos tem Ensino Fundamental, 33\% estão no Ensino Médio e 58\% integram o Ensino Superior - entre graduação e pós-graduação. Além disso, $83 \%$ dos respondentes participaram do projeto Núcleos de Iniciação ao Voleibol no Paraná, $8 \%$ participaram do projeto Super Ação no estado do Rio de Janeiro, 7\% do projeto Esporte em Ação com núcleos no estado do Rio de Janeiro e Paraná e 3\% participaram no projeto Vôlei em Rede com núcleos nos estados do Rio Grande do Sul, São Paulo, Rio de Janeiro e Rio Grande do Norte. O grande percentual de ex-alunos respondentes oriundos no projeto Núcleos de Iniciação ao Voleibol no Paraná se deve ao fato de ser neste estado que o projeto se iniciou, ou seja, já atuava por 16 anos no momento da pesquisa. Os outros projetos têm no máximo 8 anos de atuação.

Utilizamos o método quanti-qualitativo para a explicitação e leitura dos dados. As perguntas abertas e fechadas nos favoreceram essa abordagem e permitiram estabelecer as relações entre os resultados da pesquisa ao analisarmos as informações apresentadas nas 738 respostas de questionário obtidas. De acordo com Prates (2012) o uso de questionário que abordam conteúdos complexos como sentimentos, percepções, experiências que são extremamente qualitativos, também podem abarcar questões de fácil quantificação como gênero, faixa etária e tempo de permanência, etc. Entendemos que a superação da dicotomia entre método de pesquisa quantitativo e qualitativo permitiu uma interpretação dos dados mais aprofundada.

A seguir, apresentamos os resultados da pesquisa realizada com os ex-alunos. Os dados foram discutidos de acordo com as perguntas dispostas no questionário, mas sempre que possível, cruzamos as informações das respostas visando facilitar o entendimento das questões abordadas.

\section{APRESENTAÇÃO E DISCUSSÃO DOS RESULTADOS}

Das 32 perguntas fechadas e 4 perguntas abertas do questionário elaborado pelo IC foram escolhidas 8 perguntas fechadas para serem apresentadas neste artigo. As perguntas selecionadas apresentam melhor os objetivos do artigo de avaliar a efetividade da proposta e da metodologia do IC, analisando o impacto da participação de crianças e jovens em seus projetos a partir da percepção dos ex-alunos. A leitura quantitativa dos dados é feita sempre de acordo com os gráficos e as discussões são apresentadas na sequência de cada gráfico objetivando uma leitura linear das informações. 
De acordo com Coakley $(2014$, p. 4) a relação entre esporte e desenvolvimento de crianças e jovens é eventual, "o simples ato de participação esportiva entre jovens não leva a resultados de desenvolvimento regularmente identificados. Ao invés, resultados estão relacionados e dependem de uma série de outros fatores". Neste sentido, o autor elenca fatores importantes: o tipo de esporte praticado, orientações dos professores e pais, mudanças na interpretação das experiências esportivas durante o curso da vida, relações sociais formadas em conexão com a participação esportiva, cultura e normas associadas com o esporte praticado, maneira como o esporte e a experiência esportiva são integradas a vida pessoal, contexto cultural e material sobre os quais a participação ocorre e características socialmente significativas dos participantes do esporte. Alguns dos elementos citados são possíveis de identificar nos resultados apresentados pela pesquisa com os ex-alunos do IC como a avaliação dos professores feita pelos ex-alunos, a manutenção de amizades após encerrada a participação nos núcleos, o vôlei como um esporte coletivo e a relação com os valores aprendidos. Entretanto, ainda carece de mais estudo para analisar dos demais fatores elencados por Coakley que não foram contemplados nessa pesquisa.

O gráfico 01 apresenta os resultados para o questionamento referente às categorias que os ex-alunos passaram durante o período que estavam no projeto. As respostas mostram que pelo menos $34,69 \%$ participou de três das quatro categorias oferecidas pelos projetos. E $19,18 \%$ dos respondentes participaram das quatro categorias ${ }^{10}$.

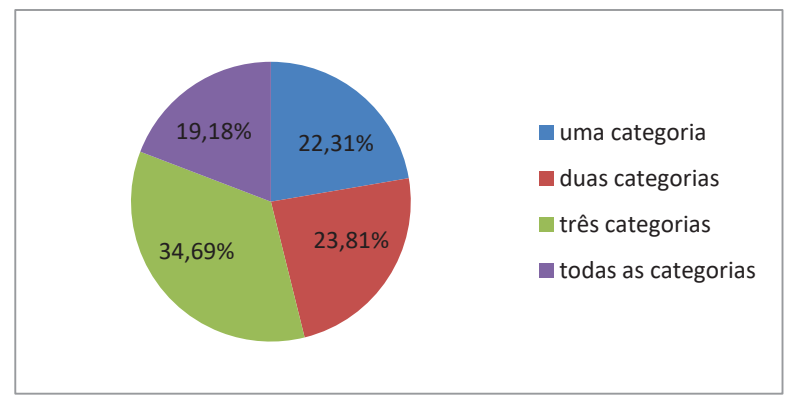

Gráfico 01 - Participação em categorias/tempo de permanência no projeto Fonte: Elaborado pelos autores.

Apesar de 53,88\% dos egressos terem permanecido por mais de dois anos no projeto, os resultados dessa pergunta apontam para a necessidade de investimento do IC no tempo de permanência dos alunos no projeto, pois quanto maior é este tempo de permanência, maiores são as probabilidades de mudanças percebidas nos comportamentos dos alunos relacionados a liderança, respeito as regras, sociabilidade e afetividade (CANDALL et al., 2013).

10 Cada categoria tem a duração de, no mínimo, um ano. Porém, os alunos podem sair a qualquer momento do projeto sem finalizar o ano de atividades. 
O tempo de permanência no projeto também tende a influenciar: 1) na interiorização de uma forma de agir com base nas experiências sociais vivenciadas no IC; 2) no incremento da rede de relações sociais formada pelos pais, colegas, professores do IC e da escola que frequentam e; 3) na incorporação de conhecimentos específicos desenvolvidos pelas aulas, viagens, palestras e demais eventos realizados pelo projeto. Em longo prazo, esses "pertences sociais" conquistados podem ser transferidos para os outros campos nos quais os agentes perpassam ao longo das suas vidas.

Quando perguntado "Você acha que aprendeu a jogar voleibol participando do projeto?", 95\% dos egressos respondentes indicaram que aprenderam a jogar bem ou muito bem, como mostra o gráfico 02 . Tais respostas apontam para a validade da Metodologia Compartilhar de Iniciação ao Voleibol.

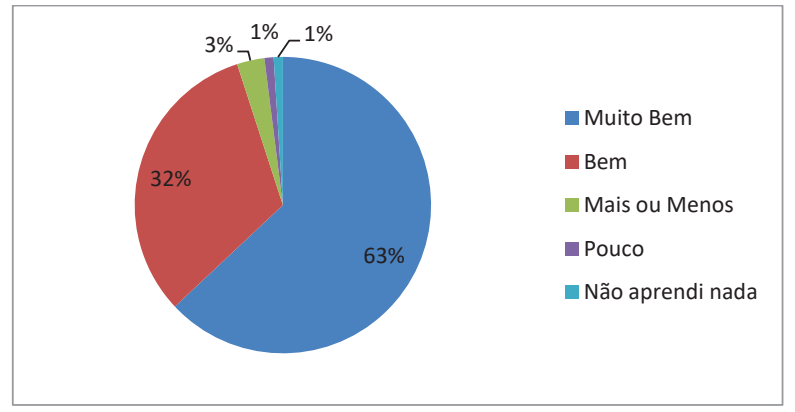

Gráfico 02 - Aprendeu a jogar voleibol participando do projeto? Fonte: Elaborado pelos autores.

O voleibol apresenta características que dificultam o engajamento na sua prática atentando para o fato de que o seu ensino é complexo, podendo gerar frustações e desinteresse caso não seja conduzido a partir de uma sequência pedagógica eficiente. O voleibol é uma modalidade em que não é possível segurar a bola e os erros na execução dos gestos técnicos implicam em pontos para o adversário desmotivando assim os que não dominam a técnica correta (OKAZAKI e PETRUNKO, 2012). As características da Metodologia Compartilhar de Iniciação ao Voleibol de redução do número de jogadores, tamanho da quadra, altura da rede, peso da bola, e adaptação das redes facilita o processo ensino-aprendizado, favorecendo a aprendizagem da modalidade.

Além do aspecto metodológico de ensino, também pode ter impactado nesses resultados a qualidade das instalações, os materiais usados nas aulas e principalmente o treinamento constante dos coordenadores e professores envolvidos no processo. A capacitação dos professores é um investimento no capital cultural dos mesmos, este que tende a ser transferido para os alunos nas trocas estabelecidas durante as aulas do IC.

O gráfico 03 mostra que $71 \%$ dos participantes da pesquisa apontaram o jogo como atividade preferida quanto perguntados sobre o que mais gostavam nas aulas. Isso 
demonstra equilíbrio na metodologia utilizada pelo IC, sem limitar a aprendizagem ao gesto técnico, oportunizando durante as aulas o momento do jogo.

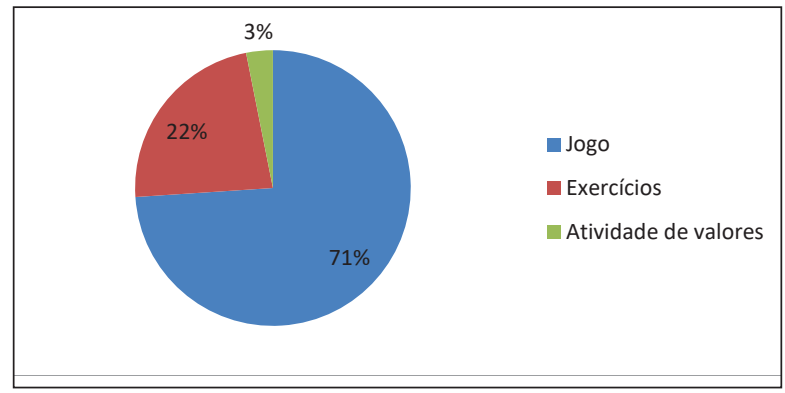

Gráfico 03 - O que mais gostava das aulas? Fonte: elaborado pelos autores.

De acordo com a Apostila de Credenciamento de Professores (2012) do IC, a aula é dividida em 3 partes: aquecimento (duração de 10 minutos), parte principal (duração de 25 minutos) e jogo (duração de 15 minutos). O aquecimento tem o foco no desenvolvimento da técnica individual através de brincadeiras. A parte principal explora exercícios que apresentem situações de jogo, com movimentos em sequências lógicas da realidade do jogo e sempre com ações encadeadas, não limitando o aluno a realizar somente uma movimentação por exercício. O jogo, com adaptações necessárias de simplificação das regras ou de gestos técnicos de acordo com o nível de aprendizagem do aluno, acontece sempre no final da aula. Esse último momento da aula pode ser realizado de maneira competitiva ou não, de acordo com os objetivos do professor naquela atividade. O material de credenciamento do IC afirma que os minutos destinados ao jogo são os mais motivadores para os alunos e o momento onde eles podem aplicar as habilidades trabalhadas durante as aulas De acordo com a literatura científica da área da aprendizagem motora, desenvolvimento motor e da pedagogia do esporte, é indicado que os jogos ocupem a centralidade do processo de iniciação esportiva, propiciando ao jogador o êxito nas tarefas e o prazer pela modalidade (MAGGIL, 2000; GALLAHUE, OZMUN, 2005; GRECO, 2007).

Apenas $3 \%$ dos ex-alunos respondentes preferiam as atividades de valores. Este resultado apontaria para um fracasso na perspectiva do ensino de valores, porém, entendemos que a interiorização de valores não ocorre numa relação de causa-efeito a partir dessas atividades pontuais e específicas, mas sim numa interdependência nem sempre planejada entre as atividades desenvolvidas no ensino do voleibol e a prática social dos alunos envolvidos. Por meio da participação nas tarefas desempenhadas nas aulas, os alunos do IC aprendem as técnicas e táticas do jogo, e, para além disso, incorporam valores a partir das situações emocionais e conflituosas que a prática de um esporte coletivo é capaz de proporcionar. 
Ao denotarmos que $92 \%$ dos respondentes atribuiu conceito 9 e 10 para os professores, conforme apresentado no gráfico 04, visualizamos que o professor é um dos elementos que contribuem decisivamente para o sucesso do processo de ensino aprendizagem do voleibol e de valores a ele associados. É a partir da identificação e admiração que os alunos cultivam por seus professores no ambiente do projeto que se torna possível a transmissão dos valores preconizados nas aulas.

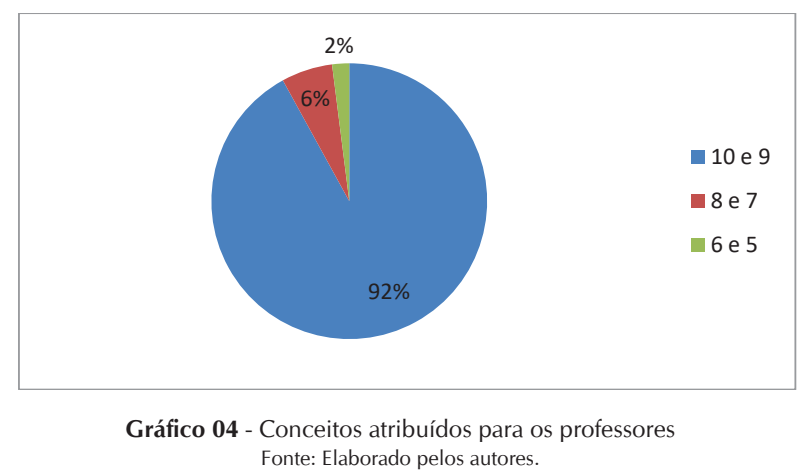

O papel do professor é fundamental na transmissão positiva ou negativa de comportamentos e quanto melhor a relação entre professores e alunos/atletas maior é o impacto a aprendizagem de comportamentos e valores (HOLT, et al., 2008; SANCHES e RUBIO, 2011). Entendemos então que ao professor é designado o papel de mediador/formador da cultura esportiva dos alunos a partir do seu planejamento, execução e avaliação das estratégias de aula adotadas, participando ativamente do complexo processo de aprendizagem esportiva e social no IC. Entretanto o processo de capacitação que os profissionais do IC são submetidos para alinhamento com as propostas filosóficas e metodológicas contribui para que o professor assuma esse papel de mediador.

O gráfico 05 aponta os resultados para a pergunta relativa à manutenção da prática de atividade física após o desligamento do projeto, 79,51\% dos respondentes afirmou que continuou praticando algum tipo de atividade física (não necessariamente o voleibol) após a saída do projeto.

É possível estabelecer uma relação positiva dos resultados sobre a manutenção da prática de atividade física e a manutenção de comportamento após a saída dos projetos do IC. Em 2013, 45,9\% da população brasileira entre 14 e 75 anos era sedentária, segundo pesquisa realizada pelo Ministério do Esporte ${ }^{11}$. Estratificando os dados dessa pesquisa por faixa etária, 32,7\% da população de 14 a 19 anos eram sedentários, 38,1\% de 20 a 24 anos e 40,7\% de 25 a 34 anos também eram sedentários. Ao considerarmos que 79,51\%

11 Pesquisa realizada pelo Ministério do Esporte sobre o perfil do praticante de atividade física no Brasil em 2013. Disponível em < http://www.esporte.gov.br/diesporte/2.html > Acesso em: 04/01/2015. 
dos egressos do IC afirmaram que continuaram praticando atividade física após o desligamento do projeto, podemos inferir que tenha ocorrido a adoção de uma determinada cultura esportiva por parte dos egressos. Essa nova cultura sugere que os ex-alunos tenham adotado um estilo de vida mais saudável, na perspectiva da manutenção dos hábitos de atividade física.

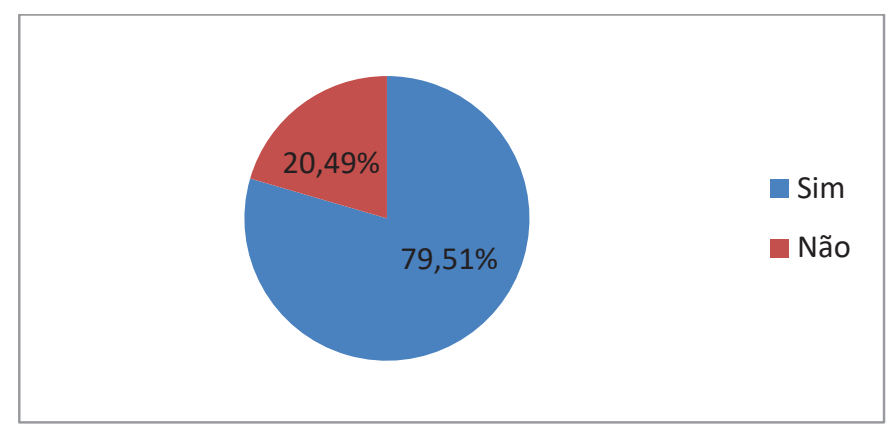

Gráfico 05 - Continua/Continuou praticando atividade física depois que saiu do projeto? Fonte: Elaborado pelos autores

O gráfico 06 apresenta os resultados para o questionamento sobre o cultivo de amizades com integrantes do projeto. A maioria dos participantes da pesquisa respondeu que sim, ou seja, $89 \%$ dos ex-alunos mantêm contatos ou relações com as pessoas que conviveram naquele mesmo período.

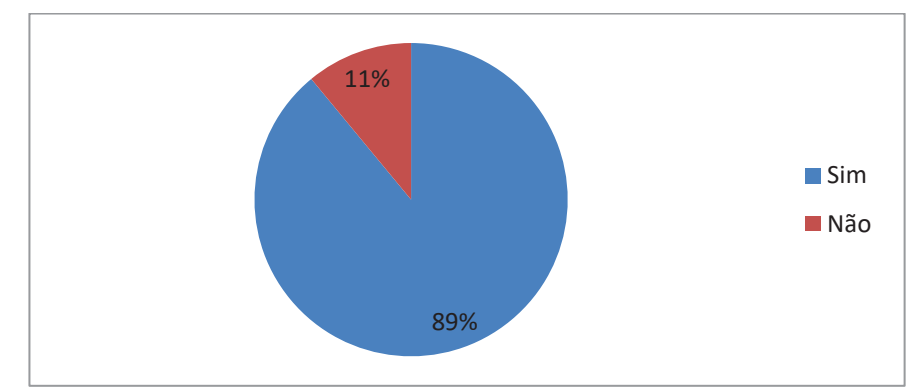

Gráfico 06 - Você ainda mantém amizade com alguém do projeto (colegas, professores)? Fonte: Elaborado pelos autores.

Perks (2007) realizou uma pesquisa para entender como a participação em atividades esportivas para jovens no Canadá influenciava no engajamento em atividades na comunidade. Segundo o autor, os achados "mostram que a participação da juventude em esportes foi relacionada positivamente ao envolvimento em atividades comunitárias. 
Os resultados da pesquisa com os ex-alunos do IC referentes à manutenção das amizades vêm ao encontro da pesquisa realizada por Perks.

A manutenção de amizades indica a hipótese de que o esporte colaborou para criação de relações sociais duráveis. Neste sentido, o fator convivência entre os alunos é fundamental para a concretização da proposta filosófica do Instituto Compartilhar, pois os mesmos estabeleceram trocas simbólicas não somente durante suas participações no IC nas aulas, jogos e demais eventos, mas continuam se relacionando após a saída do projeto, ou seja, em maior ou menor escala, transmitindo valores uns aos outros.

O gráfico 07 informa que, na opinião de $78 \%$ dos ex-alunos, o projeto socioesportivo do Instituto Compartilhar contribuiu muito para o seu próprio desenvolvimento como cidadão.

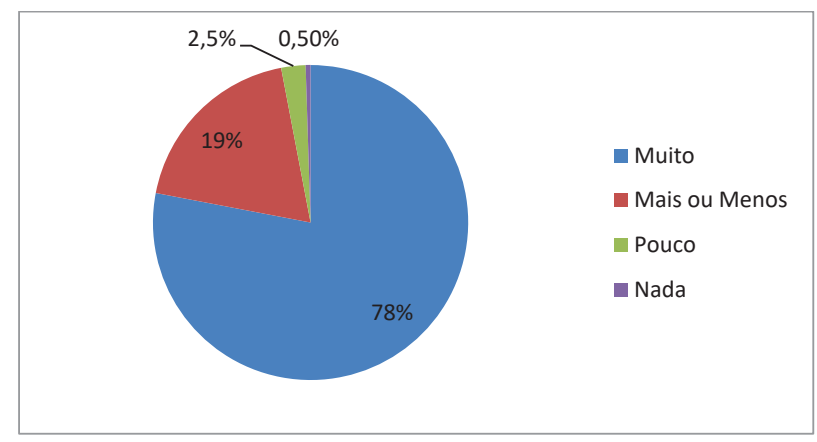

Gráfico 07 - Quanto você acha que o projeto contribuiu para o seu desenvolvimento como cidadão? Fonte: Elaborado pelos autores.

Este é um dado significativo e que pode ser discutido em duas frentes. A primeira baseia-se justamente no próprio entendimento do que significa ser cidadão, ou seja, na conscientização individual de uma construção baseada em valores sociais, éticos e morais pautada por uma matriz cultural e delimitada por um determinado período histórico. Nesse sentido, pode-se afirmar que o ex-aluno passou por esse contexto de formação durante o tempo que permaneceu no projeto.

A segunda etapa aborda uma questão nuclear um pouco mais complexa e que demandaria um tempo maior de observação e acompanhamento desses egressos. A abordagem seria: qual a relação entre o indivíduo e a sociedade? Como o indivíduo se enxerga no interior da sociedade? E como ele se posiciona diante dos conflitos e contradições sociais?

Em linhas gerais, tratando-se do conceito de cidadania, é preciso considerar que cada indivíduo sofre diversas influências relativas à posição que ocupa num determinado contexto social sendo, portanto, passível de análises a partir dessas relações e interdependências.

Os participantes da pesquisa também foram questionados sobre os valores que aprenderam no projeto. Dentre uma lista de valores previamente elencados pelo IC, os participantes assinalavam uma ou mais opções como resposta. O gráfico 08 mostra os 
seguintes valores como trabalho em equipe, respeito, reponsabilidade, comprometimento, cooperação, como os valores mais indicados pelos respondentes. Trabalho em equipe foi o valor citado por $90,40 \%$ dos respondentes da pesquisa, seguido por respeito e responsabilidade.

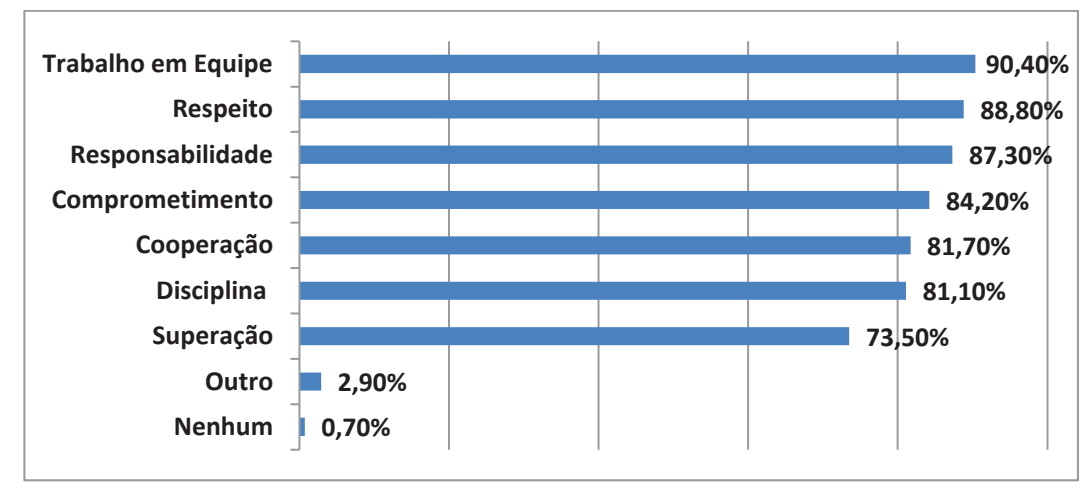

Gráfico 08 - Qual(is) valor(es) você aprendeu durante o tempo de participação no projeto? Fonte: Elaborado pelos autores

A Metodologia Compartilhar de Iniciação ao Voleibol preconiza o desenvolvimento de valores específicos por categoria. As crianças e adolescentes de cada categoria apresentam características comportamentais e de desenvolvimento psicológico que possibilitam a inserção de valores específicos de acordo com a faixa etária (INSTITUTO COMPARTILHAR, 2010). Apesar de o Instituto Compartilhar trabalhar valores específicos (cooperação, responsabilidade, respeito e autonomia) os resultados apontam para a aprendizagem de outros valores além desses. Isso demonstra uma interdependência entre os valores, ou seja, a ênfase em um valor não exclue objetivamente a compreensão de outros valores complementares. Como exemplo, pode-se afirmar que para trabalhar bem em equipe é necessário ter outros valores como respeito e comprometimento. As características do voleibol, sem contato físico e a necessidade de ser um jogo coletivo, também contribuem para o desenvolvimento de valores como a cooperação e responsabilidade (CASTANHEIRA, 2008).

A interiorização e a transferência dos comportamentos aprendidos no ambiente do projeto do IC para outros ambientes é um ponto a ser discutido. Mesmo que o questionário tenha sido respondido por ex-alunos, que já estão distante da prática cotidiana dos projetos e que as experiências esportivas tenham sido ressignificadas com as outras experiências (entrada no mercado de trabalho, constituição de família, por exemplo) é difícil mensurar a transferência dos valores e comportamentos ensinados durante a participação no IC para outros ambientes. Ainda que algumas percepções dos alunos referentes a incorporação de valores e desenvolvimento como cidadãos possam ser positivas, é necessário considerar que a interação social com outros agentes sociais (família, escola, etc) pode ter contribuído para esse cenário. 


\section{CONSIDERAÇÕES FINAIS}

A análise das respostas dos 738 ex-alunos ao questionário nos permitiu compreender em maior profundidade o alcance dos projetos do IC. A partir das respostas, o primeiro ponto a ser destacado é a eficiência da metodologia do ensino do voleibol e de valores desenvolvida pelo Instituto Compartilhar durante 17 anos. Os respondentes se mostraram familiarizados com a proposta de ensino, dado que a maioria deles assinalou terem aprendido a jogar bem/muito bem, terem continuado a praticar voleibol em momentos de lazer e terem incorporado os valores inerentes à esta modalidade esportiva coletiva no projeto.

Ficou evidente e quase unânime nas respostas ao questionário que a identificação, a significação e a aquisição de referências para agir socialmente a partir das atividades desenvolvidas no projeto ocorreram de maneira mais consistente, consciente e efetiva a partir da proximidade e admiração pelos professores. Isto demonstra que o investimento na dimensão educacional do projeto tem se efetivado, segundo a perspectiva dos ex-alunos respondentes.

Outro ponto de destaque também são as indicações de manutenção de atitudes e comportamentos aprendidos no projeto que atualmente podem interferir em ações cotidianas da inserção de ex-alunos na comunidade como a manutenção de amizades e a continuidade da prática de atividade física.

As percepções acerca dos valores incorporados pelos ex-alunos fornecem direções para uma continuidade no trabalho, preconizando a incorporação de valores sociais através da iniciação esportiva. Entretanto, é necessário considerar que a aderência dos alunos no projeto pode ser um fator limitante para incorporação de valores. Quanto maior o tempo de permanência as atividades do projeto, maior é a possibilidade de aprendizagem dos valores preconizados pelo IC. Pesquisas que abordem de maneira aprofundada essa incorporação e talvez transferência dos valores podem ajudar a confirmar as percepções identificadas nessa primeira investigação. Outras técnicas de pesquisa em ciências humanas e sociais podem auxiliar nessa comprovação.

A pesquisa apresenta limitações, se considerarmos que os ex-alunos que tiveram a iniciativa de responder a pesquisa podem ter sido somente os que melhor se identificaram com a proposta do projeto. Os alunos que não tiveram uma boa experiência no projeto não responderam ou nem mesmo ficaram sabendo da pesquisa. Assumindo que somente os ex-alunos com experiências mais positivas participaram, os resultados podem ter sido supervalorizados, sem outras opiniões para equilibrar as respostas.

Os resultados apresentados nessa pesquisa contribuem para um pequeno avanço nos estudos sobre os impactos e efetividade das ações propostas por projetos sociais. Mesmo assim, não é possível utilizar-se desses resultados e atribuir somente a participação nos projetos do IC aos bons resultados referentes ao grau de escolaridade, aprendizado de valores e contribuição para o desenvolvimento como cidadão. Muito menos generalizar esses dados para todos os 4200 alunos que são atendidos anualmente pelo IC. Ainda assim é possível considerar que o trabalho com foco no ensino de um esporte e investimento educacional em valores apresenta resultados satisfatórios, que permitem uma 
continuidade na proposta, sempre com investimento em avaliação e aperfeiçoamento da Metodologia utilizada.

Para finalizar, uma leitura possível indica que a sociedade contemporânea, dominada por uma visão consumista de mundo, está cada vez mais distante dos valores humanos que reforçam os princípios éticos e morais nas relações sociais. Nesta lógica, pode-se supor que projetos socioesportivos desta natureza dão algumas respostas, no mínimo, esperançosas em termos de contribuições educacionais e de formação cidadã.

\section{REFERÊNCIAS}

BAILEY, Richard. Evaluating the relationship between physical education, sport and social inclusion. Educational Review, v. 57, n. 1, p. 71-90, 2005.

BARBIRATO, Fernanda R. A Socialização em contextos de projetos socioesportivos: um estudo de caso na Fundação Gol de Letra. Dissertação (Mestrado em Educação). 2005. 143f. Faculdade de Educação, Universidade Federal Fluminense. Niterói, 2005.

CANDAL, Cristiana; LOBO, Thereza; OBERG, Lurdes; RIBEIRO, Claudia. Avaliação de Impacto - O que mudou? Relatório Final. 2013. Disponível em: < http://www. efeitoesporte.com.br/site/arquivo/RelatoriolmpactoEALeme2012.pdf >. Acesso em: 10 jul. 2015.

CASTANHEIRA, Maria Auxiliadora Villar. Capital Social, Sustentabilidade e Esporte: elementos para a construção de uma educação em valores a partir do esporte voleibol. 250f. 2008. Dissertação (Mestrado Acadêmico em Organizações e Desenvolvimento). UNIFAE - Centro Universitário Francisco. Curitiba. 2008.

COAKLEY, Jay. Sports in Society: Issues and Controversies. 11. ed. New York: McGranHill Education. 2014.

GALLAHUE, David Lee; OZMUN, John. Compreendendo o desenvolvimento motor: bebês, crianças, adolescentes e adultos. São Paulo: Phorte, 2005.

GIL, Antônio Carlos. Métodos e técnicas de pesquisa social. 5. ed. São Paulo: Atlas, 1999. GRECO, Pablo Juan. Iniciação esportiva universal. Belo Horizonte: UFMG, 2007.

HOLT, Nicholas L.; TINK, Lisa N.; MANDIGO, James L.; FOX, Kenneth R. Do youth learn life skills through their involvement in high school sport? A case study. Canadian Journal of Education, v. 31, n. 2, p. 281-304. 2008.

HOLT, Nicholas L., KINGSLEY, Bethan C., TINK, Lisa N., SCHERER, Jay. Benefits and challenges associated with sport participation by children and parents from low-income families. Psychology of Sport and Exercise, v. 12. n. 4, p. 490-499, set. 2011.

HOLT, Nicholas L., NEELY, Kacey C. Positive Youth Development Through Sport: a review. Revista Iberoamericana de Psicología del Ejercicio y el Deporte. v. 6, n. 2, 2011.

INSTITUTO COMPARTILHAR. Relatório Anual Atividades 04, 05, 2006. Curitiba, 2007. . Apostila de credenciamento de professores. Rio de Janeiro: 2012.

Desenvolvimento de valores na Metodologia Compartilhar de Iniciação do Voleibol. Curitiba, 2011. 
. Relatório Anual Atividades 2011. Curitiba, 2012. Disponível em: < http:// compartilhar.org.br/relatorio/2011/index.html > . Acesso em: 08 jul. 2015.

. Relatório Anual Atividades 2012. Curitiba, 2013. Disponível em < http:// compartilhar.org.br/relatorio/2012/index.html >. Acesso em: 08 jul. 2015.

. Relatório Anual Atividades 2013. Curitiba, 2014. Disponível em < http:// compartilhar.org.br/relatorio/2013/Relatorio_Anual_2013.pdf>. Acesso em: 07 jul. 2015.

. Relatório Anual Atividades 2014. Curitiba, 2015. Disponível em < http://www. compartilhar.org.br/relatorio/2014/Relatorio_Anual_2014.pdf >. Acesso em: 01 jul. 2015.

HIRAMA, Leopoldo K. Algo para além de tirar as crianças da rua: a Pedagogia do Esporte em projetos socioeducativos. 2008. 359 f. Dissertação (Mestrado). Faculdade de Educação Física, Universidade Estadual de Campinas, Campinas,2008.

$\mathrm{KOH}$, Koon Tech.; CAMIRÉ, Martin. Strategies for the Development of Life Skills and Values through Sport Programmes: Review and Recommendations. In: Emerging Trends and Innovation in Sports Marketing and Management in Asia. Editora IGI Global, p.241256, 2015.

MAGGIL, Richard. Aprendizagem motora: conceitos e aplicações. São Paulo: Edgard Blucher, 2000.

MARCHI JR, Wanderley. "Sacando" o voleibol. São Paulo: Hucitec, 2004.

MINISTÉRIO DO ESPORTE. A prática de Esporte no Brasil. (2013) Disponível em < http:// www.esporte.gov.br/diesporte/2.html > Acesso em: 04/01/2015.

OKAZAKI, Fábio; PETRUNKO, Vinícius. Estudo descritivo dos fundamentos: toque, manchete e saque por baixo do voleibol em crianças e adolescentes participantes de um programa socioesportivo do Instituto Compartilhar. Revista Científica - JOPEF, Fórum Internacional de Qualidade de Vida e Saúde, v. 13, n 1, ano 09, Curitiba: Editora Korppus, 2012.

PRATES, Jane Cruz. O método marxiano de investigação e o enfoque misto na pesquisa social: uma relação necessária. Textos \& Contextos (Porto Alegre), v. 11, n. 1, p. 116 - 128, jan./jul. 2012. Disponível em: < http://revistaseletronicas.pucrs.br/ ojs/index. php/fass/article /view/ 11647/8056> . Acesso em: 14 jul. 2015.

PERKS, Thomas. Does sport foster social capital? The contribution os sport to a lifestyle of community participation. Sociology of Sport Journal, v. 24, n. 4, p. 378-401. 2007.

SANCHES, Simone Meyer; RÚBIO, Katia. A prática esportiva como ferramental educacional: trabalhando valores e a resiliência. Educação e Pesquisa. São Paulo, v. 37, n.4, p. 825-842, dez. 2011.

SILVA, Silvio Sipliano da. Educação física escolar versus projeto social esportivo: quando os donos da casa perdem o jogo. Dissertação (Mestrado). Faculdade de Educação. Universidade de São Paulo. São Paulo, 2010.

SILVEIRA, Juliano. Desenvolvimento Humano, Responsabilidade Social e Educação no Capitalismo: investigando o programa "Educação pelo Esporte" do Instituto Ayrton Senna. 151f. 2007. Dissertação (Mestrado). Centro de Desportos. Universidade Federal de Santa Catarina. Florianópolis, 2007. 
SKINNER, James; ZAKUS, Dwight. H.; COWEL, Jacqui. Development through Sport: Building Social Capital in Disavantaged Communities. Sport Management Review, 2008, 11, 253-275.

STIGGER, Marco Paulo; THOMASSIM, Luís Educardo. Entre o "serve" e o "significa": uma análise sobre perspectivas atribuídas ao esporte em projetos sociais. Licere. Belo Horizonte, v.16, n.2, jun/2013. Disponível em: < https://seer.lcc.ufmg.br/index.php/ licere/article/view/ 382/277>. Acesso em: 06 jul. 2015.

VIANNA, José Antonio; LOVISOLO, Hugo Rodolpho. Projetos de inclusão social através do esporte: notas sobre a avaliação. Movimento, Porto Alegre, v.15, n.3, p.145-62, 2009.

VLASTUIN, Juliana. O caso da equipe de voleibol feminina Rexona (1997-2003): um estudo das inter-relações com a mídia esportiva. 161f. 2008. Dissertação (Mestrado). Departamento de Educação Física, Setor de Ciências Biológicas da Universidade Federal do Paraná. Curitiba, 2008. 


\title{
HUMAN DEVELOPMENT AND TRAMISSION OF VALUES IN INSTITUTO COMPARTILHAR'S SOCIAL AND SPORTIVE PROJECTS: the perspective of alumni
}

\begin{abstract}
The goal of this research is to analyze the impact of Instituto Compartilhar (IC) methodological proposal through the perception of the alumni who participated in its social and sportive projects. Therefore, we evaluated 738 answered online questionnaires by alumni of IC. Based on those answers, we identified that participation in a project can be indeed a possibility of internalization of social values and a contribution to human development, as $90.40 \%$ of respondents said that during the time of participation in the project, they have learned teamwork, $88.80 \%$ of them have learned how to respect and $78 \%$ said that the project contributed to their development as citizens. When we consider that $63 \%$ of former students said they learned how to play volleyball very well, we also concluded that the methodology used by IC complies with one of its primary goals which is to teach a sport.
\end{abstract}

Keywords: Instituto Compartilhar; Sportive Initiation; Values; Human Development

\section{EL DESAROLLO HUMANO Y LA TRANSMISIÓN DE VALORES EM LOS PROYECTOS SOCIALES Y DESPORTIVOS DO INSTITUTO COMPARTILHAR: la perspectiva de los exalumnos}

\section{RESUMEN}

El objetivo de esta investigación es analizar el impacto de la metodología propuesta del Instituto Compartilhar (IC) a través de la percepción de los alumnos que participaron en sus proyectos sociales y deportivos. Por lo tanto, se evaluaron 738 cuestionarios en línea a través de ex alumnos de la IC. Sobre la base de las respuestas, hemos identificado que la participación en un proyecto puede ser más bien una posibilidad de internalización de valores sociales y la contribución al desarrollo humano, ya que $90.40 \%$ de los encuestados dijo que durante el tiempo de participación en el proyecto, aprendieron a trabajo en equipo, $88.80 \%$ de ellos han aprendido a respetar y el $78 \%$ dijo que el proyecto ha contribuido a su desarrollo como ciudadano. Si tenemos en cuenta que el $63 \%$ de los ex estudiantes dijeron que aprendieron a jugar muy bien el voleibol también concluyó que la metodología utilizada por el $\mathrm{Cl}$ cumple con uno de sus objetivos es enseñar un deporte.

Palabras clave: Proyectos Sociales; Iniciación Deportiva; Valores; Desarrollo Humano

Recebido em: março/2016 Aprovado em: setembro/2016 